\title{
Molecular characterization of African swine fever viruses from Burkina Faso, 2018
}

\author{
Moctar Sidi ${ }^{1 \wedge}$, Habibata Lamouni Zerbo ${ }^{1 *}$, Bruno Lalidia Ouoba ${ }^{1}$, Tirumala Bharani K. Settypalli², \\ Gregorie Bazimo ${ }^{1}$, Hamidou Sandaogo Ouandaogo ${ }^{1}$, Boubacar N'paton Sie ${ }^{1}$, Ilboudo Sidwatta Guy ${ }^{3}$, \\ Drabo Dji-tombo Adama', Joseph Savadogo ${ }^{3}$, Anne Kabore-Ouedraogo ', Marietou Guitti Kindo', \\ Jenna E. Achenbach ${ }^{4}$, Giovanni Cattoli ${ }^{2}$ and Charles E. Lamien ${ }^{2}$
}

\begin{abstract}
Background: African swine fever (ASF) is a viral hemorrhagic disease of domestic and wild swine. ASF has been endemic in Burkina Faso since 2003. In October 2018, substantial pig deaths occurred in Ouagadougou and two neighboring municipalities in central Burkina Faso. Following these mortalities, the veterinary extension services carried out investigations to begin control measures and collect samples.

Methods: We performed real-time PCR for diagnostic confirmation and molecular characterization of the virus based on the partial P72, the complete p54, the partial CD2v, and partial B602L genes.

Results: The field study revealed that mortalities started two weeks before our investigations. The real-time PCR results confirmed ASFV DNA in twenty samples out of sixty-two blood samples collected in four different locations. The sequencing and phylogenetic analysis showed that ASFVs causing these outbreaks belong to genotype I and serogroup 4. The study of the CVR showed 4TRS variants, and that of the CD2V amino acid sequence revealed five variants based on the number of deleted KCPPPK motifs in the C-terminal proline-reach region of the protein.
\end{abstract}

Conclusions: The existence of multiple variants in these outbreaks shows the importance of molecular characterization to understand the evolution of ASFV isolates and the link between epidemics.

Keywords: African swine fever, Central variable region, B646L, B602L, E183L, Burkina Faso

\section{Background}

African swine fever (ASF) is a viral disease caused by the ASF virus (ASFV), an Asfivirus of the family Asfarviridae and can affect both wild and domestic pigs.

ASF causes a drop in animal production and affects livestock productivity due to high mortality that can reach $100 \%$ in outbreaks involving highly virulent strains. Due to this high mortality, the disease has a significant impact on low-income countries.

*Correspondence: habiouermi@gmail.com

1 Laboratoire National d'Elevage, Ouagadougou, Burkina Faso

Full list of author information is available at the end of the article
Globally, ASF continues to spread and has expanded its geographical distribution to four continents: Africa, Europe, Asia, and America [1,2].

In West Africa, ASF was first reported in 1978 in Senegal and spread to Ivory Coast in 1996, followed by Cape Verde, Togo, and Nigeria in 1997, Benin and Ghana in 1999, and Burkina Faso in 2003 [3-7]. In 2018 alone, Benin, Ivory Coast, Niger, Nigeria, Togo, Ghana, Senegal, Bissau Guinea reported 79 outbreaks [8].

Burkina Faso has an estimated pig population of $2,345,803$ [9]. ASF is now endemic in the country, affecting the livelihood of smallholder farmers and food security at a national level. For instance, Burkina Faso 
reported 32 ASF outbreaks to OIE between 2014 and 2018, affecting 14 provinces.

Since there is no vaccine for ASF, disease control mainly relies on early detection and implementation of control measures such as animal movement restriction, restricted access to infected areas, stamping out, and proper carcass disposal [10]. Besides, is equally important to consistently characterize outbreak strains to assess how the disease is spreading to better implement control measures. There are molecular tools capable of detecting all ASFV genotypes, serogroups, and additional gene variant analysis to characterize strains within various genotypes [11-15].

Currently, there are twenty-four known ASFV genotypes [16, 17], all of which have been detected in Africa. Europe and Asia [18] has experienced both genotypes I and II.

In October 2018, there was a report of high mortality of pigs in Ouagadougou and surrounding areas in the Kadiogo province (Fig. 1), prompting the deployment of field investigation teams from the veterinary extension services to implement control measures.
The present study details our findings during the field investigation and the molecular characterization of isolates collected during these outbreaks.

\section{Materials and Methods}

Study area, outbreak investigation, and sample collection The study covered four farms in the peri-urban region of Ouagadougou (Fig. 1). All suspicions of ASF cases were from semi-intensive farms with a herd size of 30 to 100 pigs. The field investigations collected information on farm management, history of diseases, examination of dead and sick animals, and sample collection. Blood samples were collected on EDTA-treated tubes from Sixtytwo sick animals at different locations in Ouagadougou (Table 1) and taken to the Laboratoire National d'Elevage, Ouagadougou, for diagnostic confirmation.

\section{Nucleic acids extraction and amplification}

DNA was extracted from blood using DNeasy ${ }^{\circledR}$ Blood \& Tissue kit (Qiagen, Hilden, Germany), according to the manufacturers' instructions. ASFV DNA detection was

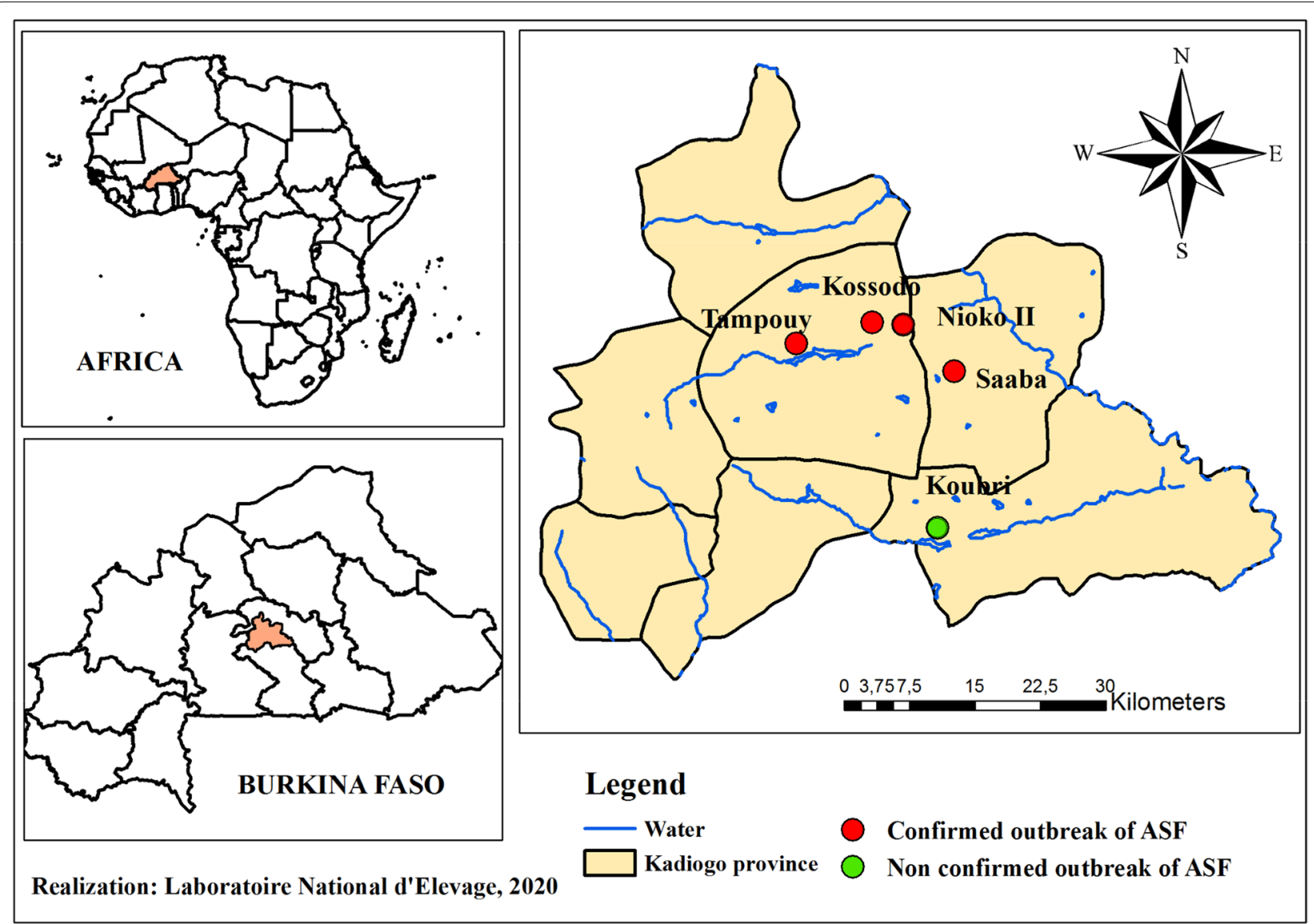

Fig.1 Map showing the ASF outbreak suspicion areas in Ouagadougou and surroundings (Kadiogo province) in central Burkina Faso. The red zones circle indicates the confirmed outbreaks, and the green the non-confirmed ones 
Table 1 Outbreak informations and samples of this study

\begin{tabular}{lllll}
\hline Sampling location & Morbidity & Mortality & Sample collect date & $\begin{array}{c}\text { Number } \\
\text { of samples } \\
\text { collected }\end{array}$ \\
\hline Ouagadougou/ Kossodo & $100 \%$ & $91 \%$ & 10 October 2018 & 10 \\
Ouagadougou/ Nioko II & $100 \%$ & $100 \%$ & 10 October 2018 & 15 \\
Saaba & $30 \%$ & $100 \%$ & 02 October 2018 & 16 \\
Ouagadougou / Tampouy & $100 \%$ & $57 \%$ & 18 October 2018 & 12 \\
Koubri & & & & 9 \\
Total & & & & $\mathbf{6 2}$ \\
\hline
\end{tabular}

performed by real time PCR, using an adaptation of a previously described procedure [19].

\section{Molecular characterization of African swine fever virus}

Three different genomic targets of the ASFV genome were amplified and sequenced using previously described methods with primers: P72-U- 5`-GGCACAAGTTCG GACATGT-3' and P72-D-5 '-GTACTGTAACGCAGC ACAG-3` [20] for the C-terminal region of the B646L gene encoding the p72 protein, P54F-5'-GCCTGCGGA TTCTGAAGATA-3'and P54R- 5`-AGGACGCAATTG CTTAAACG -3` [12] for the complete E183L gene encoding the p54 protein, ORF9RLW_F-5`-AATGCG CTCAGGATCTGTTAAATCGG-3` and ORF9RLW_R$5 `$-TCTTCATGCTCAAAGTGCGTATACCT -3` [21] for the central variable region (CVR) of the B602L gene.

To determine the serogroups of the 2018 ASFV isolates from Burkina Faso, the partial CD2v gene [22] was amplified and sequenced using two sets of primers ga3611for- $\quad 5^{`}$-TATAATATAACAAATAATTGTAG3', ga4220rev-5 '-AGGGACGCATGTAGTAAATAG3`, ga4124f-5 '-CTGAATCTAATGAAGAAGA-3` and ga4698r-5 -AAGTCTTTGTAGGTTTTTCGTTCA-3` to generate two overlapping fragments. Briefly, a mixture consisting of $12.5 \mu \mathrm{L}$ of the 2X Q5 High-Fidelity Master Mix (Neb Inc), $500 \mathrm{nM}$ of each primer, and $2 \mu \mathrm{L}$ of the template DNA was set up in a total reaction volume of $25 \mu \mathrm{L}$. The following thermal profile was used for amplification: initial denaturation at $95{ }^{\circ} \mathrm{C}$ for $5 \mathrm{~min}$, then 40 cycles of denaturation at $95^{\circ} \mathrm{C}$ for $45 \mathrm{~s}$, annealing at $52{ }^{\circ} \mathrm{C}$ for $45 \mathrm{~s}$ and elongation at $72{ }^{\circ} \mathrm{C}$ for $90 \mathrm{~s}$, and final elongation at $72{ }^{\circ} \mathrm{C}$ for $5 \mathrm{~min}$.

The amplified PCR products were purified using Wizard SV Gel and PCR Clean-Up kit, according to the manufacturer's protocol (Promega Corporation, Madison, WI, USA) and sequenced by LGC Genomics (Berlin, Germany). The raw sequences were assembled and edited using Vector NTI 11.5 Software (Life Technologies, Carlsbad, CA, USA). The nucleotide sequences of ASFV isolates of Burkina Faso were deposited in
GenBank under accession numbers MT851949 to MT851967 (p54 gene), MT851968 to MT851986 (p72 gene), MT851987 to MT852005 (B602L gene), and MT852006 to MT852019 (CD2v gene). For comparative analysis, additional ASFV sequences were retrieved from GenBank. Multiple sequence alignments were performed with MUSCLE as implemented in MEGA software version 7 [23].

For phylogenetic analysis of the p72 gene fragments, a data set of 93 nucleotide sequences (398 characters) was prepared, including 19 sequences from this study and additional sequences from GenBank with at least one representative of each of the 24 known ASFV genotypes and the sequences of some historical samples from Burkina Faso and neighboring countries. A Neighbor-Joining (NJ) tree was produced for the p72 gene in Mega 7 using the Maximum Composite Likelihood method, with the data being re-sampled 1,000 times using the bootstrap method.

For the p54 tree, the dataset consisted of 63 taxa (453 characters), including 19 sequences from this study and additional sequences from GenBank with at least one representative of each of the 18 ASFV p72 genotypes for which a 554 sequence is available. Historical sequences from Burkina Faso and neighboring countries were also included in the dataset. A Minimum Evolution tree was constructed using the p-distance substitution model and the Close-Neighbor-Interchange (CNI) algorithm. The initial tree was generated using the Neighbor-joining algorithm. All positions with less than $95 \%$ site coverage were removed. The data were re-sampled 1,000 times using the bootstrap method.

A maximum-likelihood (ML) tree of the partial CD2v amino acid sequences was constructed applying the predetermined CpREV $+\mathrm{G}$ model. The dataset included representatives of the eight known ASFV serogroups and ASFVs clustering outside the eight established serogroups. For each phylogenetic reconstruction, the robustness of the tree topology was assessed using 1000 bootstrap replicates. 
For each isolate, the CVR nucleotide sequence was translated into amino acid, and the deduced amino acid tetramers were matched with previously reported codes [11, 13, 24-26]. The CVR sequences were analyzed together with those of historical isolates from Burkina Faso and other Western African countries.

\section{Results}

\section{Outbreak investigations}

The affected farms consisted of semi-intensive production systems with open-air housing and free-ranging animals kept under reduced biosecurity levels. The investigations revealed that the disease had started several days to two weeks prior to the visit by our field team to the Saaba farm. The affected farms had introduced new animals without observing an initial quarantine period. In addition, several butchers visited the farms to acquire animals for slaughtering. Typically, the butchers visit several farms to obtain pigs, then transport the purchased animals to meat processing sites increasing the risk for further disseminating the disease. In three farms located in the peri-urban area of Ouagadougou, $100 \%$ morbidity was observed, with a fatality rate varying between 57 and 100\% (Table 1). The farm in Saaba had low morbidity, however, it presented $100 \%$ mortality (Table 1). The first outbreak occurred in Saaba, followed by Nioko II, Kossodo, and Tampouy. These four localities have in common a network of roads connecting them, thus facilitating the trade of animals between the sites and connecting them to pig slaughtering sites. The diseased pigs showed depression, inappetence, and skin redness, especially on the ears with petechiae. They also had hyperthermia, reduced mobility, and lethargy. Unfortunately, fresh carcasses were not available for necropsy.

\section{Laboratory diagnosis}

The real-time PCR results confirmed ASFV DNA in twenty, out of sixty-two blood samples, from the four different locations (Fig. 1) and distributed as follows: seven positives in Kossodo, seven in Nioko II, three in Saaba, and three in Tampouy. Nine samples from Koubri tested negatives.

\section{Molecular characterization}

We successfully sequenced nineteen partial p72 and p54 genes, fourteen partial $\mathrm{CD} 2 \mathrm{v}$ genes, and twenty partial B602L.

In the p72 phylogenetic analysis, all 2018 ASFV from Burkina Faso clustered within ASFV genotype I (Fig. 2), suggesting that only genotype I ASFVs caused these outbreaks. The analysis of the p54 sequences showed that all Burkina Faso ASFV isolates of this study belong to the genotype Ia subgroup (Fig. 3). However, a close inspection of the multiple sequences alignments of the nucleotide and amino acid sequences of the P54 gene showed that, although they all belong to genotype Ia, the 2018 isolates of Burkina Faso comprised two sub-groups based on the complete length of the p 54 gene (552 bp, and $564 \mathrm{bp}$ ). The difference was due to a deletion of 12 nucleotides. The amino acid sequences showed that the deletion occurred in a region flanked by "ATGG" and "SAHP" and containing a series of 2 or 3 repeats of the four amino acids "PAAA" (Table 2) and Fig. 4.

The phylogenetic tree of the CD2v partial amino acid sequences showed that all sequenced isolates belong to serogroup 4 (Fig. 5). The multiple sequence alignment of the amino acid sequences of the $\mathrm{CD} 2 \mathrm{v}$ protein showed that the proline-rich region near the C-terminal comprised variable number repeated units of KPCPPP (Fig. 6). Therefore, based on the number of deleted PCРPРК units, the isolates could be segregated into groups 0 , 2, 3, or 4 missing units of the KPCPPP repeats (Table 2). Three variants with 0 , 2, and 4 missing KPCPPP units were present on the farm at Kossodo. The ASFVs in Saaba had three missing KPCPPP units, those in Tampouy had four missing KPCPPP units, and those in Nioko II had 0 units missing.

The analysis of 20 CVRs revealed four variants of the tetrameric repeat sequence (TRS) with 32, 24, 23, and 12 TRS (Table 2).

Three out of the four CVR variants of this study (Table 2) shared motifs beginning with "ABNAAA" and ending with "CBNAFA" flanking additional TRS. The CVR with 12 TRS was present in Saaba, the index outbreak (September 28, 2018), and in two subsequent outbreaks in Nioko II and Kossodo (Table 2). In Nioko II, there was an additional profile with 24 TRS, unique to this farm, for which, unfortunately, we could not sequence the p72. In Kossodo, there were two other profiles with 23 and 32 TRS, the former being identical to the pattern found in the fourth outbreak that occurred on October 11, 2018, in Tampouy.

\section{Discussion}

Since its first discovery in 2003 [5], ASF has been endemic in Burkina Faso.

An epizootic of African swine fever in 2008, and the one in 2018, led to significant losses in the pig production sector of the country and neighboring countries of Benin, Ivory Coast, Niger, Togo, and Ghana.

The trade of live animal and animal products and intensive movement of people between the porous borders of these countries can explain the transboundary persistence of ASF.

Our finding that ASF genotype I caused these outbreaks is consistent with previous reports showing that 


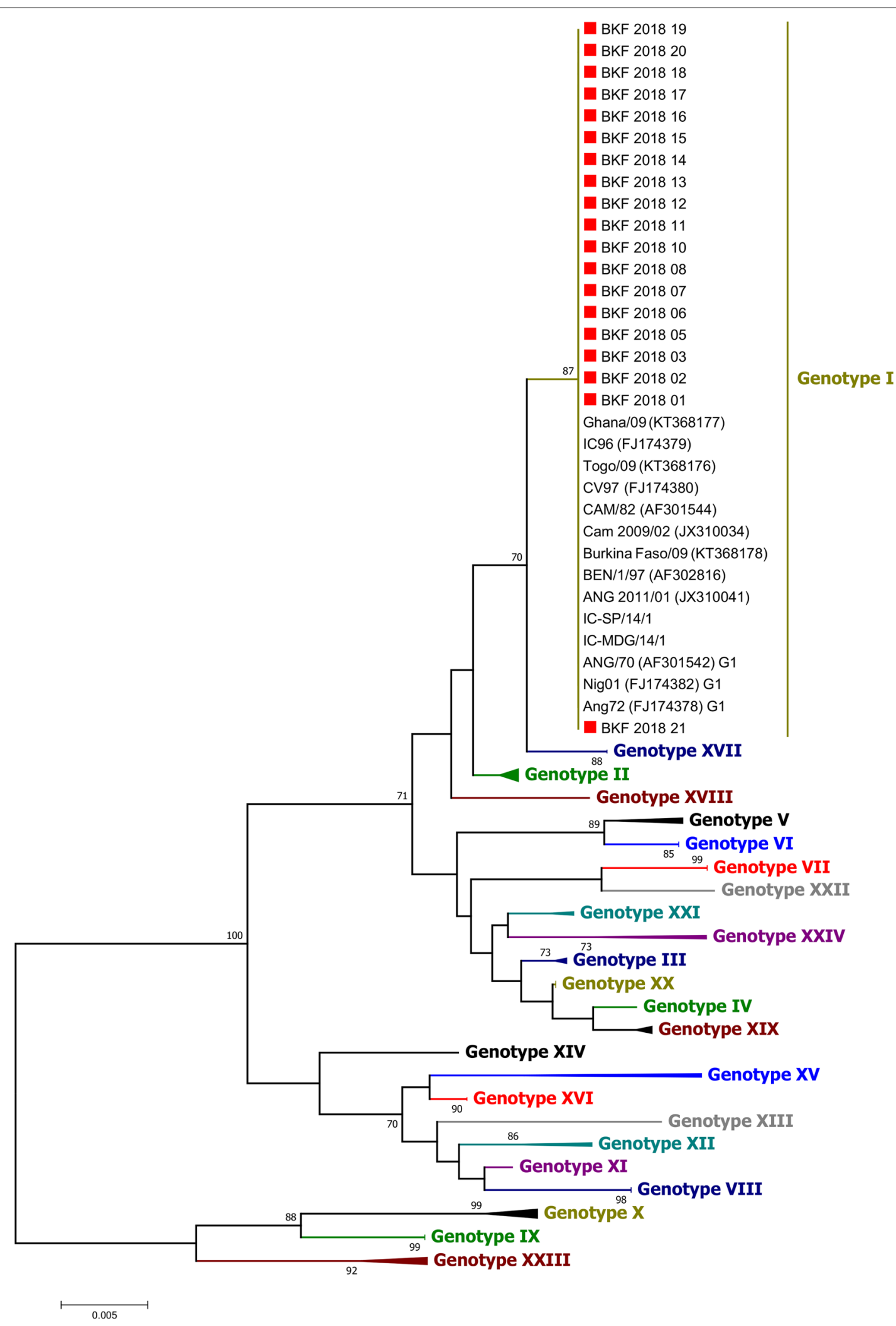

Fig. 2 Neighbor-joining tree of the partial p72 gene, depicting genetic relationships of the 2018 ASFV isolates from Burkina Faso (highlighted with red diamonds) with representatives of the 24 known ASFV genotypes. The evolutionary distances were computed using the Maximum Composite Likelihood method. Bootstrap values $>70 \%$ are shown 


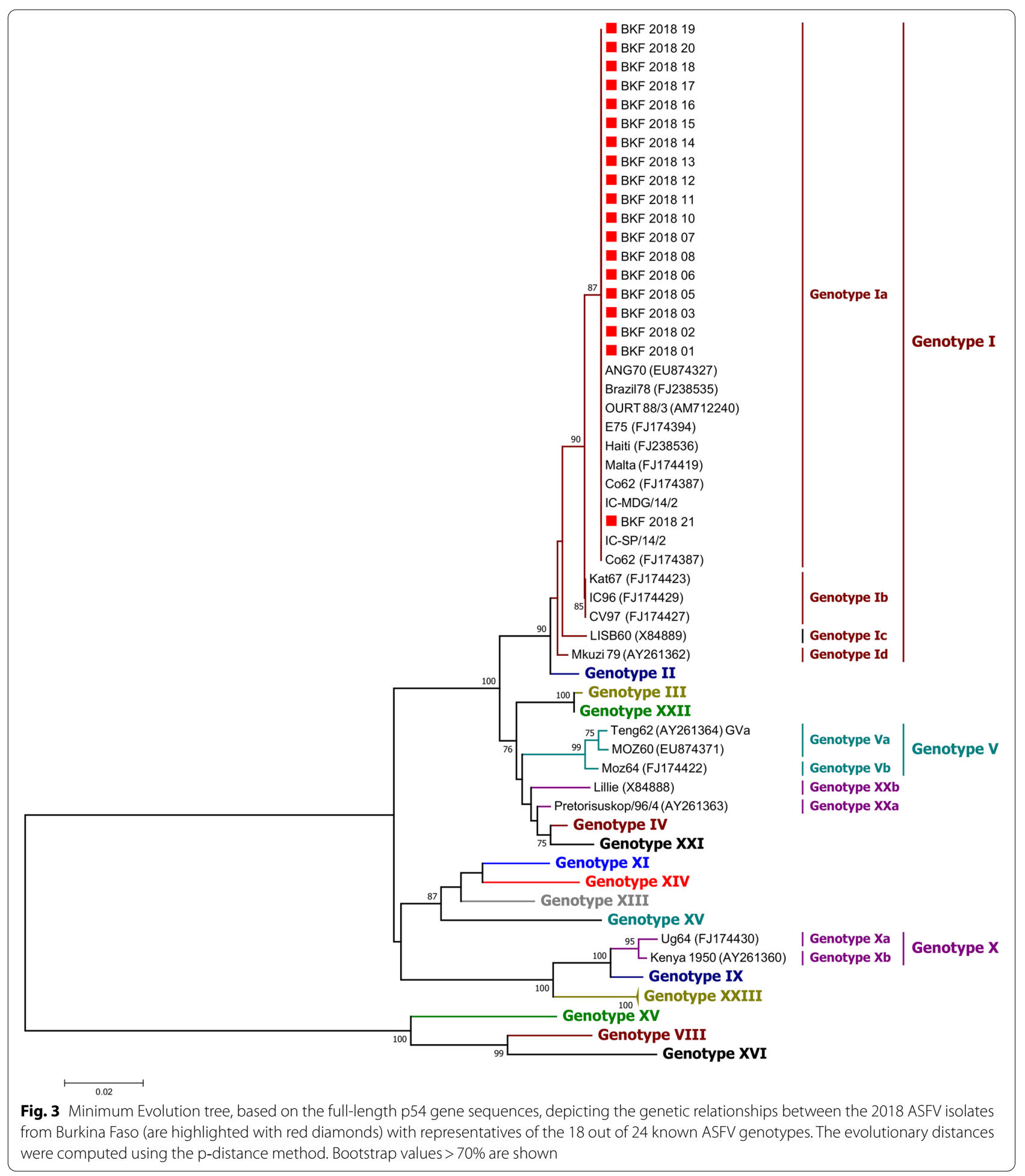

this genotype was the only one circulating in West Africa $[16,27-29]$.

Nonetheless, it is worth noting that ASFV genotype II has been reported recently in Nigeria [30]. In central
Africa, only genotype I ASFV is present in Cameroon [31]. Other Central African Countries also have genotype I, co-circulating with genotype IX in Chad and the Central African Republic, and genotype IX and XIV in DRC 
Table 2 Comparison of the CVR, p54 and CD2v (C-terminal) profiles of the 2018 ASF outbreak isolates from Burkina

\begin{tabular}{|c|c|c|c|c|c|c|}
\hline Isolate name & CVR & $\begin{array}{l}\text { Number of } \\
\text { repeats (CVR) }\end{array}$ & $\begin{array}{l}\text { p54 (PAAA } \\
\text { repeats) }\end{array}$ & $\begin{array}{l}\text { CD2v (number of } \\
\text { deleted PCPPPK) }\end{array}$ & Location & Outbreak date \\
\hline BKF_2018_01 & ABNAAAAAAACAAAAAACBNAFA & 23 & 3 & 2 & Kossodo & 28-Sep-18 \\
\hline BKF_2018_02 & ABNAAAAAAACAAAAAACBNAFA & 23 & 3 & 2 & Kossodo & 28-Sep-18 \\
\hline BKF_2018_03 & ABNAAAAAAACAAAAAACBNAFA & 23 & 3 & 2 & Kossodo & 28-Sep-18 \\
\hline BKF_2018_05 & ABNAAAAACBNAAAAACBNAAAAAAACBNAFA & 32 & 3 & 4 & Kossodo & 28-Sep-18 \\
\hline BKF_2018_06 & ABNAAACBNAFA & 12 & 2 & 0 & Kossodo & 28-Sep-18 \\
\hline BKF_2018_07 & ABNAAACBNAFA & 12 & 2 & 0 & Kossodo & 28-Sep-18 \\
\hline BKF_2018_08 & ABNAAACBNAFA & 12 & 2 & 0 & Kossodo & 28-Sep-18 \\
\hline BKF_2018_09 & AAAABNABBNABBAABBNABNABA & 24 & 2 & ND & Nioko II & 29-Sep-18 \\
\hline BKF_2018_10 & ABNAAACBNAFA & 12 & 2 & 0 & Nioko II & 29-Sep-18 \\
\hline BKF_2018_11 & ABNAAACBNAFA & 12 & 2 & 0 & Nioko II & 29-Sep-18 \\
\hline BKF_2018_12 & ABNAAACBNAFA & 12 & 2 & 0 & Nioko II & 29-Sep-18 \\
\hline BKF_2018_13 & ABNAAACBNAFA & 12 & 2 & 0 & Nioko II & 29-Sep-18 \\
\hline BKF_2018_14 & ABNAAACBNAFA & 12 & 2 & 0 & Nioko II & 29-Sep-18 \\
\hline BKF_2018_15 & ABNAAACBNAFA & 12 & 2 & 0 & Nioko II & 29-Sep-18 \\
\hline BKF_2018_16 & ABNAAACBNAFA & 12 & 2 & 3 & Saaba & 23-Sep-18 \\
\hline BKF_2018_17 & ABNAAACBNAFA & 12 & 2 & 3 & Saaba & 23-Sep-18 \\
\hline BKF_2018_18 & ABNAAACBNAFA & 12 & 2 & 3 & Saaba & 23-Sep-18 \\
\hline BKF_2018_19 & ABNAAAAACBNAAAAACBNAAAAAAACBNAFA & 32 & 3 & 4 & Tampouy & $11-$ Oct-18 \\
\hline BKF_2018_20 & ABNAAAAACBNAAAAACBNAAAAAAACBNAFA & 32 & 3 & 4 & Tampouy & $11-$ Oct-18 \\
\hline BKF_2018_21 & ABNAAAAACBNAAAAACBNAAAAAAACBNAFA & 32 & 3 & 4 & Tampouy & 11-Oct-18 \\
\hline
\end{tabular}

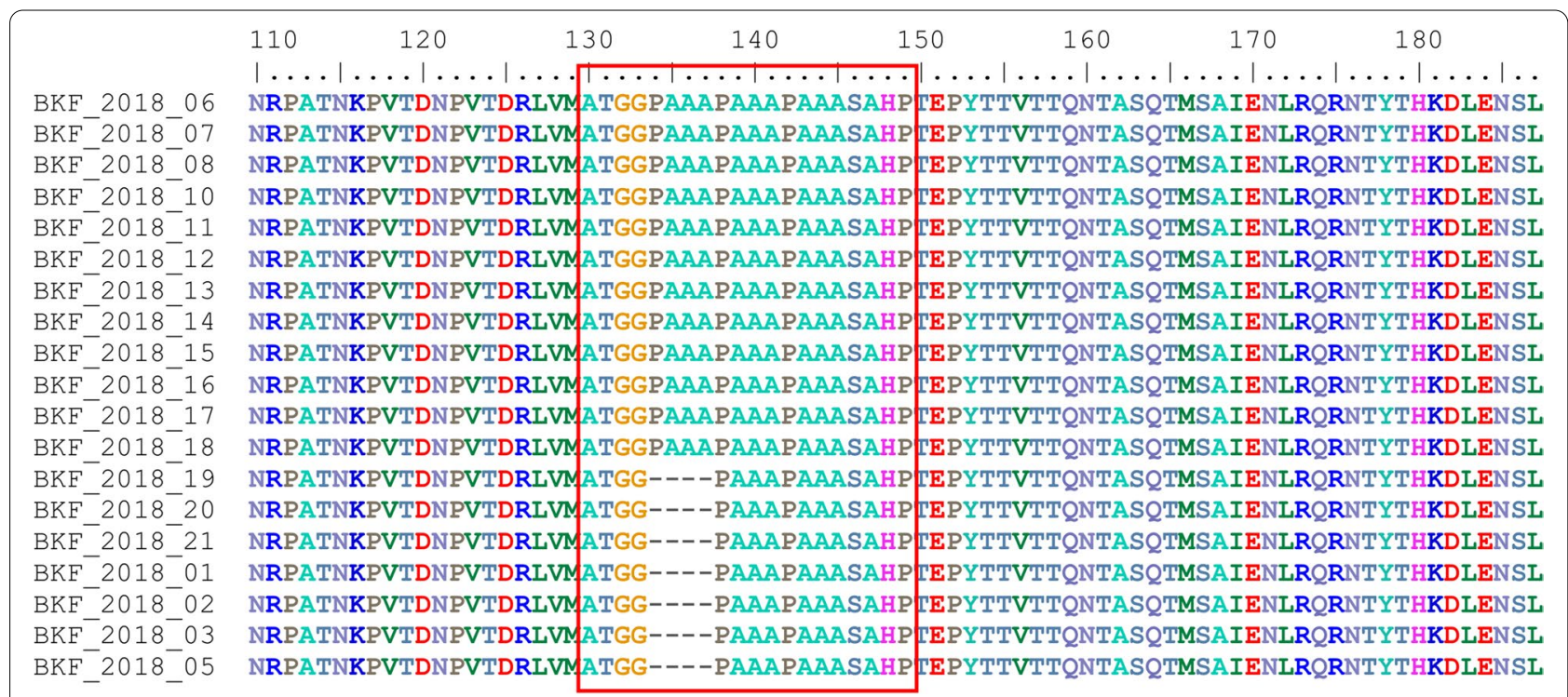

Fig. 4 Comparison of the 2018 ASFV isolates from Burkina Faso using the amino acid sequences of the p54 protein. The partial representation of the multiple sequence alignment shows the amino acid sequences variation among the isolates (inside the red box)

(See figure on next page.)

Fig. 5 Maximum Likelihood tree based on the partial amino acid sequences of the CD2v protein. The tree shows the relationship between the 2018 ASFV isolates from Burkina Faso (highlighted with red diamonds) and the representatives of the eight known ASFV serogroups and ASFVs clustering outside the eight established serogroups. The General Reversible Chloroplast Model with Gamma distribution (cpREV+G) was used. Bootstrap values higher than $70 \%$ are shown 


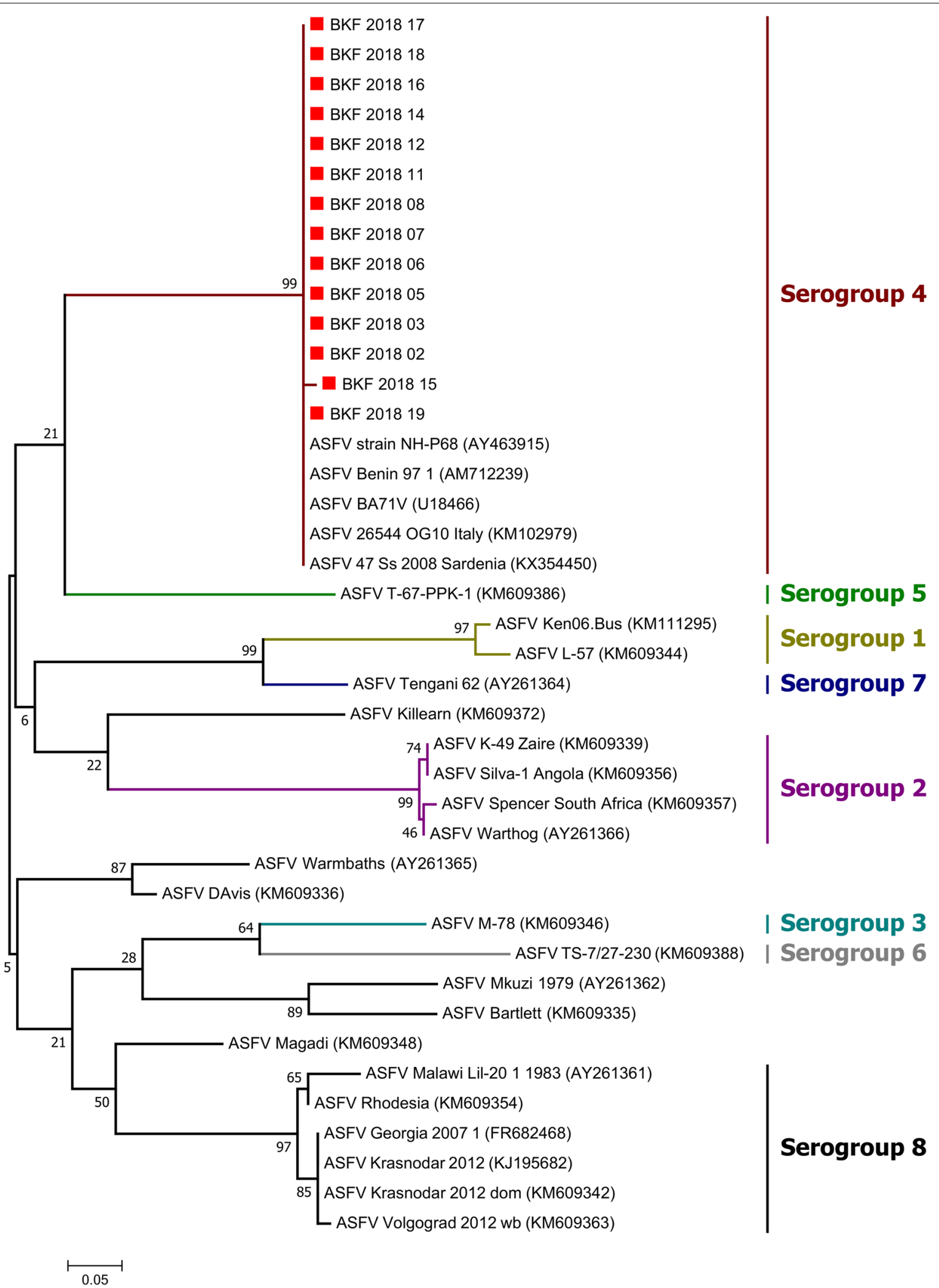

Fig. 5 (See legend on previous page.) 


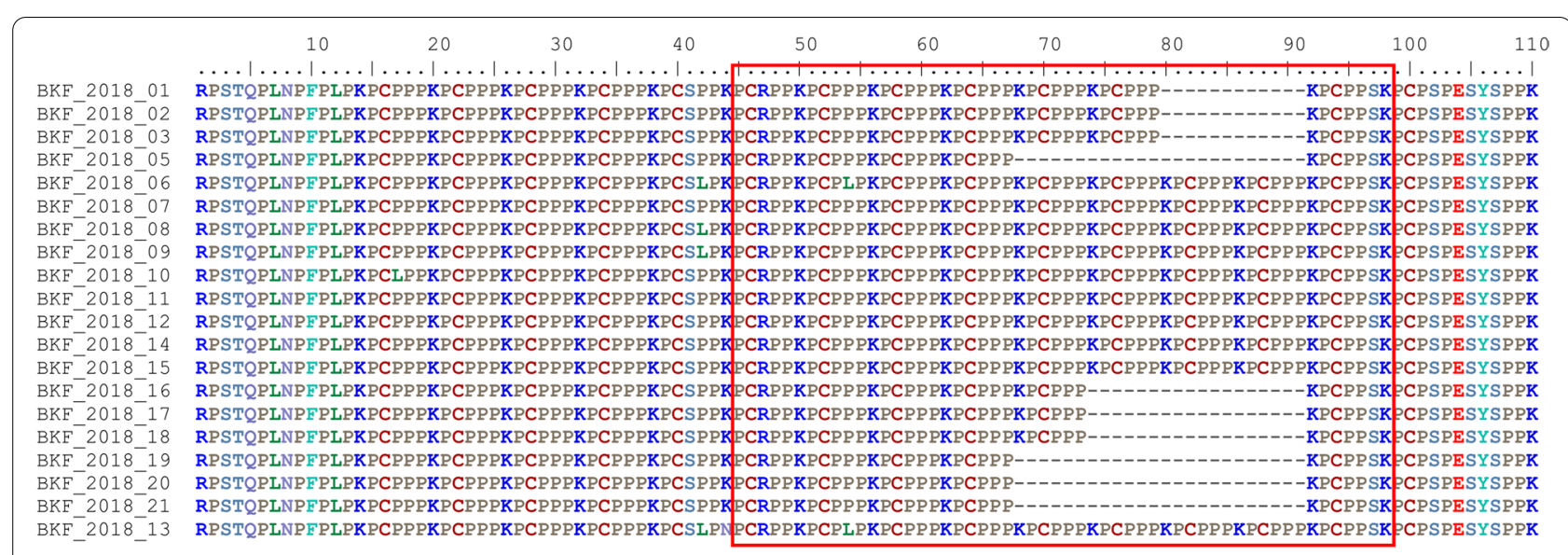

Fig. 6 Comparison of the 2018 ASFV isolates from Burkina Faso using the C-terminal of the CD2v protein. The partial representation of the multiple sequence alignment shows the amino acid sequences variation in the $\mathrm{C}$-terminal of the CD2v protein (inside the red box)

[12]. The analysis of the CVR in the 2018 samples showed four variants of the tetrameric repeats. An earlier study of samples collected between 2007 and 2010 [28] showed ten variants of the tetrameric repeats, all different from those found in this study, making fourteen variants identified in the country, between 2007 and 2010 and 2018.

In this study, there were three TRSs variants, two p54 profiles, three $\mathrm{CD} 2 \mathrm{v}$ variants in Kossodo, and two different TRSs variant Nioko II.

Saaba, Nioko II, and Kossodo shared a common ASFV variant with 12 TRS in the CVR, suggesting an epidemiological link between those three outbreaks. The variant with 12 TRS from Saaba had three KPCPPP units deleted at the C-terminal of its CD2v, differentiating it from the 12 TRS variants of Nioko II and Kossodo with no missing KPCPPP unit. Saaba, Nioko II, and Kossodo are three nearby locations with direct connections and frequent trade activities. The onset dates of these outbreaks, between September 23 and September 28, 2018, support the hypothesis that the disease spread from the first outbreak in Saaba to the neighboring sites of Nioko II and Kossodo. Similarly, ASFV BKF_2018_05, a 32 TRS variant collected in Kossodo on September 28, 2018, had identical TRS, CD2v, and p54 profiles to all ASFV collected in Tampouy during an outbreak that started on October 11, 2018. The detection of identical viruses and the date of the outbreaks in the two locations suggest a spread of ASFV from Kossodo to Tampouy.

It is unclear why multiple ASFV variants are present in Kossodo and Nioko II but could suggest multiple introductions of the disease within those farms. It is also possible that the virus mutated while spreading within those farms. Previous reports have suggested changes in the CVR sequence during adaptation of ASFV to cell cultures [21] and during ASF epidemics [12, 16].
Our study suggests that the proline-rich region near the $\mathrm{C}$-terminal of the $\mathrm{CD} 2 \mathrm{v}$ gene is suitable for genotype I ASFV isolates discrimination.

Using genotype I and serogroup 4 isolates recovered during 2018 outbreaks in central Burkina Faso, we have shown that the number of deleted KPCPPP units in the proline-rich region of the $C D 2 \mathrm{v}$ protein varied substantially, enabling it to be an additional mean to discriminate ASFVs. Hence, our study confirms an earlier report that analysis of the number of PCPPPK repeats provided an additional mean, similar to the analysis of the CVR profile [32]. Further investigations will establish whether this approach is suitable to analyses of other ASFV serogroups and genotypes.

Surprisingly, our field investigations determined that the pig breeders know little about common diseases of swine, especially African swine fever. In addition, there is insufficient technical support and minimal effort to increase pig breeder and community awareness of ASF.

The pig production system in Burkina Faso is based mainly on a traditional extensive system with household free-ranging pigs and small to medium semi-intensive farming systems mainly in peri-urban areas. The housing comprises shelters made with local material in extensive systems or semi-modern to modern housing in the semiintensive system [33]. In most farms, brewers' grains and swill are the primary feeds for the pigs.

Near and between the farms, there is a lack of proper biosecurity practices, promoting several diseases, including ASF [33]. Additionally, other domestic animals like cattle, sheep, goats, dogs, rodents, and birds are freeranging and share common space with pigs; therefore, they could also spread diseases. These conditions raise the need for increased awareness of transboundary animal diseases and continued rapid diagnostics and 
analysis to identify and understand future outbreaks. For instance, additional outbreaks of ASF occurred in new locations in the country since those described in this paper. Although there was no evidence for an epidemiological link between the recent outbreaks and those described in this paper, the continuous occurrence of ASF outbreaks highlights inadequate disease management. This instigated the veterinary authorities to start implementing active surveillance to better monitor ASF and characterize the circulating genotypes of the ASF virus."

\section{Conclusion}

We have shown that ASFVs belonging to genotype I, serogroup 4, caused four outbreaks in October 2018 in Burkina Faso. There were 4 TRS variants based on the CVR analysis and five based on the number of deleted KCPPPK motifs in the $\mathrm{C}$-terminal proline-reach region of the CD2v protein, showing that the latter can serve as an additional tool for ASFV isolates discrimination. Further studies are needed to understand how these variants have emerged. The presence of multiple variants involved in these outbreaks shows the importance of molecular characterization to understand the evolution of ASFV isolates and the link between epidemics.

\section{Abbreviations \\ ASF: African swine fever; ASFV: African swine fever virus; CVR: Central Variable Region; CNI: Close-Neighbor-Interchange; DNA: Deoxyribonucleic acid; DRC: Democratic Republique of Congo; NJ: Neighbor-Joining; TRS: Tetrameric Repeat Sequence.}

\section{Acknowledgements}

We are very grateful to the veterinarian of the Department of Livestock Services, who helped a lot in the sample collection. This study was supported by VETLAB network initiative of the Joint FAO/IAEA Division.

\section{Authors' contributions}

Conceived and designed the experiments: SM, HLZ, IG; Performed the experiments: SM, HLZ, KA, GM, DD, SJ; Analyzed the data: CEL, OLB, HLZ; Contributed reagents/materials/analysis tools: TBKS, JEA, GC, CEL; Wrote the paper: SM, HLZ, OLB, IG; Supervised the study: SJ; Edited the final manuscript:TBKS, JEA GC, CEL, OLB, HLZ. All authors read and approved the final manuscript.

\section{Funding}

Not applicable

\section{Availability of data and materials}

The data that support the findings of this study are openly available in NCBI at https://www.ncbi.nlm.nih.gov/nucrore

\section{Declarations}

\section{Ethics approval and consent to participate}

The authors confirm that the ethical policies of the journal, as noted on the journal's author guidelines page, have been adhered to. All clinical and diagnostic data included within the study formed part of veterinary diagnostic investigations. Samples from veterinary interventions for disease treatment and control fall under article 30 of the Animal Health and Veterinary Public Health Act 2017 (LOI N $048-2017 / A N$ ) of Burkina Faso and do not require further ethical approval, as the purpose is to maintain the health and welfare of animals. The outbreaks investigation was authorized by the General Directorate of Veterinary Services (letter N²018_11_MRAH/SG/DGSV). Informed oral consent to participate was obtained from the owners.

\section{Consent for publication}

Not applicable

\section{Competing interests}

All authors declared that they have no competing interests.

\section{Author details}

${ }^{1}$ Laboratoire National d'Elevage, Ouagadougou, Burkina Faso. ${ }^{2}$ Animal Production and Health Laboratory, Joint FAO/IAEA Division of Nuclear Techniques in Food and Agriculture, Department of Nuclear Sciences and Applications, International Atomic Energy Agency, Vienna, Austria. ${ }^{3}$ Direction Générale Des Services Vétérinaire, Ouagadougou, Burkina Faso. ${ }^{4}$ Battelle Memorial Institute, 1001 Research Park blvd, Charlottesville, VA 22901, USA.

Received: 8 October 2021 Accepted: 20 January 2022

Published online: 12 February 2022

\section{References}

1. OIE WO for AH. African Swine Fever (ASF) Report $N^{\circ} 34$ : December 20, 2019 to January 03, 2020. 2020. https://www.oie.int/fileadmin/Home/ eng/Animal_Health_in_the_World/docs/pdf/Disease_cards/ASF/Report_ 34_Current_situation_of_ASF.pdf. Accessed 17 Apr 2020.

2. OIE. OIE-WAHIS. 2021. https://wahis.oie.int/\#/report-info? reportld=36844. Accessed 13 Sep 2021.

3. el Hicheri K, Gomez-Tejedor C, Penrith ML, Davies G, Douati A, Edoukou GJ, et al. L'epizootie de peste porcine africaine de 1996 en Cote d'Ivoire [The 1996 epizootic of African swine fever in the Ivory Coast]. OIE Rev Sci Tech. 1998:17:660-73.

4. Odemuyiwa SO, Adebayo IA, Ammerlaan W, Ajuwape ATP, Alaka OO, Oyedele Ol, et al. An outbreak of African Swine Fever in Nigeria: Virus isolation and molecular characterization of the VP72 gene of a first isolate from West Africa. Virus Genes. 2000;20:139-42.

5. UA-BIRA. Annuaire panafricain de la santé animale 2004. 2004.

6. Rweyemamu M, Paskin R, Benkirane A, Martin V, Roeder P, Wojciechowski K. Emerging Diseases of Africa and the Middle East. Ann N Y Acad Sci. 2006;916:61-70.

7. Babalobi OO, Olugasa BO, Oluwayelu DO, ljagbone IF, Ayoade GO, Agbede SA. Analysis and evaluation of mortality losses of the 2001 African swine fever outbreak, Ibadan. Nigeria Trop Anim Health Prod. 2007;39:533-42.

8. OIE WO for AH. OIE World Animal Health Information System. 2020. https://www.oie.int/wahis_2/public/wahid.php/Diseaseinformation/ statusdetail. Accessed 17 Apr 2020.

9. INSD. ANNUAIRE STATISTIQUE 2017. Ministère de l'économie, des finances et du développement, BURKINA FASO; 2018. http://www.insd.bf/n/conte nu/pub_periodiques/annuaires_stat/Annuaires_stat_nationaux_BF/ Annuaire_Statistique_National_2017.pdf. Accessed 14 Apr 2020.

10. Gavier-Widén D, Ståhl K, Dixon L. No hasty solutions for African swine fever. Science. 2020;367:622-4.

11. Achenbach JE, Gallardo C, Nieto-Pelegrín E, Rivera-Arroyo B, DegefaNegi T, Arias M, et al. Identification of a New Genotype of African Swine Fever Virus in Domestic Pigs from Ethiopia. Transbound Emerg Dis. 2017:64:1393-404.

12. Mulumba-Mfumu LK, Achenbach JE, Mauldin MR, Dixon LK, Tshilenge CG, Thiry E, et al. Genetic assessment of african swine fever isolates involved in outbreaks in the Democratic Republic Of Congo between 2005 and 2012 reveals co-circulation of p72 genotypes I, IX and XIV, including 19 variants. Viruses. 2017;9:31.

13. Gallardo C, Mwaengo DM, MacHaria JM, Arias M, Taracha EA, Soler A, et al. Enhanced discrimination of African swine fever virus isolates through nucleotide sequencing of the p54, p72, and pB602L (CVR) genes. Virus Genes. 2009:38:85-95.

14. Yu M, Morrissy CJ, Westbury HA. Strong sequence conservation of African swine fever virus 172 protein provides the molecular basis for its antigenic stability. Arch Virol. 1996;141:1795-802. 
15. Rodriguez F, Alcaraz C, Eiras A, Yáñez RJ, Rodriguez JM, Alonso C, et al. Characterization and molecular basis of heterogeneity of the African swine fever virus envelope protein p54. JVirol. 1994;68:7244-52.

16. Couacy-Hymann E, Kouakou KV, Achenbach JE, Kouadio L, Koffi YM, Godji $H P$, et al. Re-emergence of genotype I of African swine fever virus in Ivory Coast. Transbound Emerg Dis. 2019;66:882-96.

17. Quembo CJ, Jori F, Vosloo W, Heath L. Genetic characterization of African swine fever virus isolates from soft ticks at the wild life/domestic interface in Mozambique and identification of a novel genotype. Transbound Emerg Dis. 2018;65:420-31.

18. Sun E, Huang L, Zhang X, Zhang J, Shen D, Zhang Z, et al. Genotype I African swine fever viruses emerged in domestic pigs in China and caused chronic infection. Emerg Microbes Infect. 2021;10:2183-93.

19. King DP, Reid SM, Hutchings GH, Grierson SS, Wilkinson PJ, Dixon LK, et al. Development of a TaqMan ${ }^{\circledR}$ PCR assay with internal amplification control for the detection of African swine fever virus. J Virol Methods. 2003;107:53-61.

20. Bastos ADS, Penrith ML, Crucière C, Edrich JL, Hutchings G, Roger F, et al Genotyping field strains of African swine fever virus by partial p72 gene characterisation. Arch Virol. 2003:148:693-706.

21. Irusta PM, Borca MV, Kutish GF, Lu Z, Caler E, Carrllo C, et al. Amino acid tandem repeats within a late viral gene define the central variable region of African swine fever virus. Virology. 1996;220:20-7.

22. Malogolovkin A, Burmakina G, Tulman ER, Delhon G, Diel DG, Salnikov N, et al. African swine fever virus CD2v and C-type lectin gene loci mediate serological specificity. J Gen Virol. 2015;96:866-73.

23. Kumar S, Stecher G, Tamura K. MEGA7: Molecular Evolutionary Genetics Analysis Version 7.0 for Bigger Datasets. Mol Biol Evol. 2016;33:1870-4.

24. Nix RJ, Gallardo C, Hutchings G, Blanco E, Dixon LK. Molecular epidemiology of African swine fever virus studied by analysis of four variable genome regions. Arch Virol. 2006;151:2475-94.

25. Lubisi BA, Bastos ADS, Dwarka RM, Vosloo W. Molecular epidemiology of African swine fever in East Africa. Arch Virol. 2005;150:2439-52.

26. Boshoff Cl, Bastos ADS, Gerber LJ, Vosloo W. Genetic characterisation of African swine fever viruses from outbreaks in southern Africa (19731999). Vet Microbiol. 2007;121:45-55.

27. Chapman DAG, Tcherepanov V, Upton C, Dixon LK. Comparison of the genome sequences of non-pathogenic and pathogenic African swine fever virus isolates. J Gen Virol. 2008;89:397-408.

28. Alkhamis MA, Gallardo C, Jurado C, Soler A, Arias M, Sánchez-Vizcaíno JM. Phylodynamics and evolutionary epidemiology of African swine fever p72-CVR genes in Eurasia and Africa. PLoS ONE. 2018;13:e0192565.

29. Luka PD, Achenbach JE, Mwiine FN, Lamien CE, Shamaki D, Unger H, et al. Genetic Characterization of Circulating African Swine Fever Viruses in Nigeria (2007-2015). Transbound Emerg Dis. 2017;64:1598-609.

30. Adedeji AJ, Luka PD, Atai RB, Olubade TA, Hambolu DA, Ogunleye MA, et al. First-Time Presence of African Swine Fever Virus Genotype II in Nigeria. Microbiol Resour Announc. 2021;10:e00350-21.

31. Wade A, Achenbach JE, Gallardo C, Settypalli TBK, Souley A, Djonwe G, et al. Genetic characterization of African swine fever virus in Cameroon, 2010-2018. J Microbiol. 2019:57:316-24.

32. Sanna G, Dei Giudici S, Bacciu D, Angioi PP, Giammarioli M, De Mia GM, et al. Improved Strategy for Molecular Characterization of African Swine Fever Viruses from Sardinia, Based on Analysis of p30, CD2V and I73R/ I329L Variable Regions. Transbound Emerg Dis. 2017;64:1280-6.

33. FAO. Secteur Porcin Burkina Faso. Rev Natl l'élevage la Div la Prod la santé Anim la FAO. 2012;No. 1., Ro.

\section{Publisher's Note}

Springer Nature remains neutral with regard to jurisdictional claims in published maps and institutional affiliations. 